\title{
The impact of cultural drivers on trust: A multi-level study of self-importance, idealism and unethical marketing behavior
}

\author{
Atya Mehreen*
}

\begin{abstract}
The purpose of this study is to find the impact of culture drivers on trust a multilevel study of self-importance, idealism and unethical marketing behavior. It is precisely explore the role of cultural drivers in developing ethical ideology and the association between the consumer's ethical ideology and his or her perception concerning the unethical marketing behavior of firms. This study based on qualitative approach and survey conducted on 350 consumers that are having age 18 and above with random sampling method. The item was derived from two sources and that are measured on five point likert scale. Data were collected randomly from general public of Karachi. The structural equation modeling equation is used to test the hypothesized relationship among the variables of the model. The study established the individualism is essential in developing self-importance attitude as well as power distance is importance for lead to idealistic attitude. Self-importance is detected to have positive relationship with the unethical marketing behavior and idealism was found to have negative relationship with unethical marketing behavior. The element of unethical marketing behavior is price and promotion has positive relationship with trust.
\end{abstract}

Keywords: unethical marketing behavior, consumer trust, marketing trust, consumers, cultural drivers, ethical ideology.

*(PhD Scholar at Iqra University), Currently teaching at KASBIT University, Visiting faculty at Ilma University 


\section{Introduction}

The main problem is facing by the marketers to get the consumers trust. For this purpose, the marketer had to acquire a number of exposures for example making new product, launching support services and getting innovative market experience with the intention to increase their market and financial performance. Marketing is mainly observable by many stakeholders and the organizational dealing put together marketing scholars and practitioners for the responsive ethical issues, the focus of this research is to explain the cultural drivers and trust outcomes of consumer perception of organizational unethical marketing behaviors. The concept of increasing ethical marketing is to enhance the organizational marketing guidelines and actions distinguished by transparency, honesty, and accountability. Nevertheless, current indication has been undoubtedly exposed with the basis of consumer trust is incompletely drive in in ethical concerns affecting to the managerial marketing actions ${ }^{1}$. Trust can be describing the consumers' motivation to depend on their anticipations for an organization's behavior in future. The organization's has considered trust, customer satisfaction and word of mouth main significant marketing outcomes. The past research's, explain that, there are two types of satisfaction which are called encounter satisfaction and relationship satisfaction and that is also called overall satisfaction ${ }^{2}$. Furthermore, the majority of researchers treat them as completely adverse for good judgment to the one of high levels complemented through low levels of others or vice versa. Studies reveal that work attitude play a positive impact on ethics, in addition to this customers as well as consumer is concerned in employees and finally there is increase number of customers in term of satisfaction, which is cause of retaining customer to the product. At the same time, communications and connection with the firm providing ethical standing can emphasize customers' feeling of confidence. Customers realize ethical standing as a proxy and substitute for reliability and quality of service in selecting providers. They are motivated to denote informally as well as socially inclined products and services to their relatives as a way of supporting causes significant to them. A firm's ethical environment fosters positive attitudes and customer slanted behaviors

1 Leonidas C Leonidou et al., Cultural Drivers and Trust Outcomes of Consumer Perceptions of Organizational Unethical Marketing Behavior, 2013, https://doi.org/10.1108/030905 61311297445.

2 Gianfranco Walsh et al., "The Effect of Consumer Confusion Proneness on Word of Mouth , Trust , and Customer Satisfaction," 2010, https://doi.org/10.1108/0309056101 1032739. 
towards sales in term of salespeople, and ultimately results in sophisticated customer satisfaction. Throughout customer-employee collaborations, when employees show positive atmospheres and impetuous, customer's positive feelings are enhanced ${ }^{3}$.

According to past studies that are reviewed for this research the current situation is the impact of influential aspect of cultural uniqueness of consumer ethical perceptions to certain extent that unethical marketing issuestaking place beginning entirely fundamentals of the marketing combination components. Firms did not fulfill their promises related to marketing mix elements. Moreover, the consumers are effected from the unethical marketing practices of the firms and consumers are losing their trust on the firms just because of they are not provided benefits as they promised regarding FMCGs product in general. Further, if the problem is not addressed firm has to pay the consequences; they will lose the trust of consumers and willingness. Consumers will go for some new substitutes. Nevertheless, to the best of my knowledge this study is not been conducted in Pakistani context. Hence, still there is the need to explain the study on cultural driver on trust mediating consumer insights of firm's unethical marketing behavior in Pakistani scenario.

The objective of the research overcome the difficulty with the impact of cultural drivers on trust mediating unethical marketing behavior, idealism and self-importance on firm regarding FMCGs firms (daily use product like shampoo, soap, beauty creams etc.) in Pakistani scenario in general.

To find out the impact of cultural drivers on trust mediating unethical marketing behavior, idealism and self-importance on firm regarding FMCGs firms.

\section{Significance of the study}

This study could be helpful for stakeholders, managers, marketer and top management as well as consumers also. Hence, the study will aid the firms to develop their trust on consumers regarding their products as they promote them. They are ask to response through questionnaire to describe about their perception and trust towards unethical marketing behavior.

3 Jay Prakash Mulki and Fernando Jaramillo, "Ethical Reputation and Value Received: Customer Perceptions," 2011, https://doi.org/10.1108/02652321111152891. 


\section{Limitation of the Study}

In this study, there are some limitations. Firstly, the sample size was only of 350 respondent from public having the age from 18 and above from Karachi. Second, lack of financial assistance from the institution. Third, limited time to complete the work that is also a big limitation. Forth, research instrument was very lengthy and respondents are not interested to fill 58 items in the questionnaire. Fifth, respondents are not able to understand the items on the spot make them understand was quite difficult and time consuming but I try my best.

\section{Scope of the Study}

The study was conducted only in Karachi due to lack of resources and limited time. In research study period is a major concern. Limited time and limited resources create hurdles in conducting research. Sample size could have expanded and different statistical technique used to analyses the impact of cultural drivers on trust with mediating role self-importance, idealism and unethical marketing practices. Further, the item should be fewer to get better response otherwise respondent would not give proper responses and try to avoid in facilitating in conducting research study.

\section{Theoretical background}

Literature this section divided into two sections. First one talk about the Theoretical Background as well as second one based on Empirical Studies In this section, it is going to describe all about the variables.

\section{Cultural Dimension and Orientation}

Cultural measurements encompass power distance, individualism, uncertainty avoidance, masculinity, as well as sequential orientation. Moreover, the past two decades the measurements, individualism have done extensively talk about with a foundation for distinct differentiation among societies ${ }^{4}$.

4 Shih-Ting Yu Long-Chuan Lu, Hsiu-Hua Chang, "Online Shoppers ' Perceptions of eRetailers ' Ethics, Cultural," 2013, https://doi.org/10.1108/10662241311295773. 


\section{Individualism and Self-Importance}

Here individualism cultures, individuals are liable to put bigger meaning continuously accomplishing objectives than on sustaining pleasant relationship. It has been described 10that individualism/collectivism like an important mediator among service quality plus the tourists' fulfillment between their online purchase ${ }^{5}$.Individualistic people are likely to analysis themselves seeing that self-determining of public organizations plus put bigger importance on self-reliance as well as individual deed. Furthermore, as this self-interested tactic stands to egoistical constructing block in their mind-set besides performance, in view of the fact that self-publicists create ethical decisions care continuously to help their durable benefits. It is empirically established that strong aspiration to behave individually is significantly to selfish actions ${ }^{6}$. By the support of argumentation and confirmation, it is a proven fact that the advanced the opinion of individualism the single has, the higher the point of self-importance as well as pride he/she possesses.

\section{H1: Individualism significantly impact on Self Importance}

\section{Masculinity and Self-Importance}

Masculinity is element of cultural orientation. In which, cultural direction is masculinity, that is, individuals differentiated through masculinity be inclined 1to strive used for material accomplishment plus worth whatever is strong, large, and fast. In addition, that people are extraordinarily competitive, take action happening a self-centered attitude, and appearance for superior presentation at somewhat cost. Moreover, they have been driven by individual victory and personal increase and are probable to put selfishness beyond the welfares of others and influenced with prescribed codes of ethics and not relationship-oriented. The entire distinctiveness point out that and single through a great mark of masculinity is responsible to construct up a great level of self-importance, by way of selfpublicists are categorized by a sensible selfishness, self-interested, and selfactualization method ${ }^{7}$.

\footnotetext{
Long-Chuan Lu, Hsiu-Hua Chang.

6 Leonidou et al., Cultural Drivers and Trust Outcomes of Consumer Perceptions of Organizational Unethical Marketing Behavior.

7 Leonidou et al.
} 
H2: Masculinity significantly impact on Self Importance

\section{Power distance and Idealism}

Power distance is the feature of a person's cultural positioning that is define to degree that fewer powerful persons reach a decision so that power is circulated unfairly. Furthermore, inequality take place in every culture, different individual's believe unstable levels of injustice and further highlighting on faces of power, such as household, religion, and law. Through the belief of superior, they are tending to be conventional to societal norms and fulfill. Moreover, for the reason that individuals distinguish by extraordinary power distance carelessly monitor upper authority and higher honorable responsibility and rules, which are the spirit of idealism, therefore the greater the opinion of power distance the individual takes, the higher the opinion of idealism they owns 8 .

\section{H3: Power Distance positively effect on Idealism}

\section{Uncertainty avoidance and Idealism}

Uncertainty avoidance of one more cultural dimension that is described by the degree of an individual is able to manage successfully through undefined, unstructured, undistinguishable, unpredictable, or unrevealed circumstances. Individuals differentiated by an in height measure of uncertainty avoidance remain essentially worried by means of safety in life and have a preference clear hierarchical formation. In addition, it has not been appreciate divergence from set practices, intolerance in the direction of irregular ideals and activities. Furthermore, stay away from uncertainty in their procedures and apparent any ambiguities individuals have a tendency to accept regulations and norms, therefore the upper the idea of uncertainty avoidance the individual takes, the higher the argument of idealism they owns ${ }^{9}$.

H4: Uncertainty Avoidance positively impact on idealism

Leonidou et al.

Leonidou et al. 


\section{Ethical ideology and unethical marketing behavior}

Idealism could be refer to the amount of desirable consequences attain by providing the right actions are taken. It is considered by the idealists that actions are taken by the individuals, not reasonable harming other individuals. In fact, individuals those have higher level of idealism other undesirable in the direction of unethical on the entire corporate actions. They are more dangerous of precise dishonest marketing actions. Therefore, it has been identified that idealistic consumers fewer accepting of marketing unethicality slightly than fewer idealistic customers' questionable marketing practices and the observed level of companies' unethical marketing activities ${ }^{10}$.

H5: Ethical ideology positively impact on unethical marketing behavior

\section{Self-Importance and unethical marketing behavior}

Egoistic individuals are uncaring near the organization's unethical marketing applies, since personal interests at risk is not putting by them shown by the empirical studies. Furthermore, egoism is defined as an individual places his/her own comfort greater than others do. Hence, egoists acquire a sort of emotional separation to less concerned by others, less caring, and potentially obvious wrongs for example risky products, price unfairness, and deceiving advertising and that is why higher level of self-importance the individual takes, the poorer the apparent rank of businesses' unethical marketing manners ${ }^{11}$.

H6: Self-importance negatively impact on unethical marketing behavior

\section{Unethical marketing behavior and trust}

The organizational actions seeing that stimulus approaching to take positive actions are reflecting on consumer behavior theory. Here, the organizational unethical marketing behavior is projected by numeral reaction to irritate consumer. Therefore, one significant response is trust that is faith or promise is trustworthy and the customer going to accomplishing whichever responsibilities in an interchange association. Definitely, the

Leonidou et al.

11 Leonidou et al. 
marketing mix troubles the consumer's trust in firms ethical performs. Furthermore, a significant relationship between organizational marketing ethicality and consumer trust was recognized by different researches. On the other hand, consumers have negative ethical perceptions about organization's marketing activities that had to locate fewer trust in particular organization.

H7: Unethical marketing behavior negatively effects on trust.

\section{Trust}

Trust can be describing the consumers' motivation to trust on their opportunities for a firm's upcoming behavior ${ }^{12}$. At this point, it is seen on highest point of the marketplace and conceptualize and the totality of consumers' readiness to rely on many firms' upcoming behavior. The firm's has considered trust, customer satisfaction and word of mouth main significant marketing outcomes. Furthermore, customer loyalty and (constructive) customer word of mouth message in the marketing literature the same as key relationship marketing outcomes in banks. Here the Canadian sampling, empathy with reliability be establish to be the most significant predictors of satisfaction along with loyalty, while in the Tunisian sample, reliability and 'responsiveness be the mainly necessary predictors of satisfaction and loyalty. The recommendation by the researcher are Canadian bank managers should differentiate the implication of empathy in service delivery during implementing proper customer-oriented strategies. Tunisian bank managers should focus on performing promised services constantly and perfectly.

12 Walsh et al., "The Effect of Consumer Confusion Proneness on Word of Mouth , Trust, and Customer Satisfaction." 


\subsection{Theoretical model}

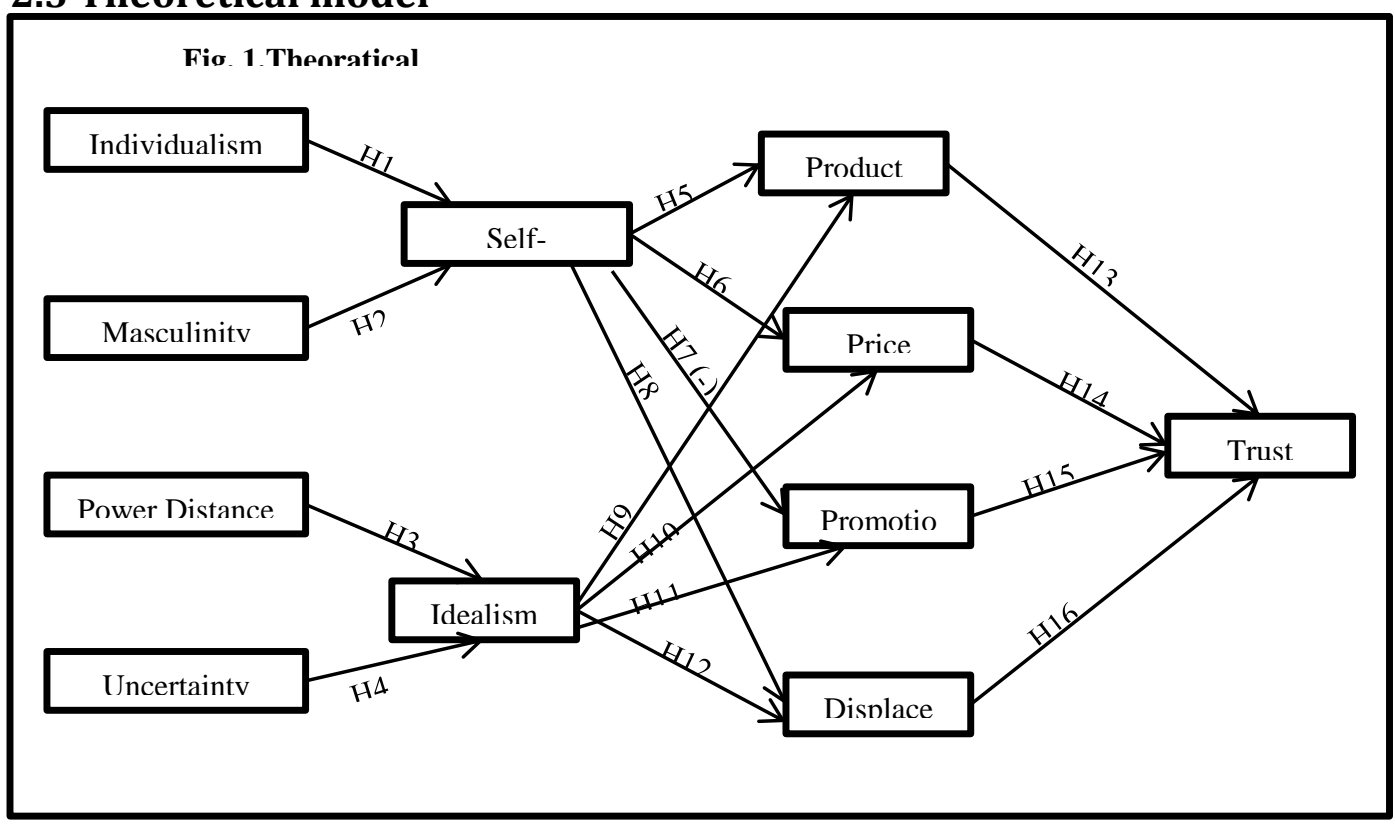

Individualism Product Self Importance Masculinity Price Trust Power Distance Idealism Uncertainty Avoidance Promotion Displacement The model represents by the helping of theories, the cultural magnitude that are individualism plus masculinity, mutually are affecting self-importance. In other hand, cultural orientation that is power distance as well as uncertainty avoidance, are persuade idealism. Further, idealism and self-importance have an effect on consumer insight relating to the unethical practices of firms with believe all of the basics of the marketing mix. Therefore, that supposed marketing unethicality is expected to manipulate the point of consumer trust in selling firms ${ }^{13}$.

\section{Methodology}

In this chapter, research methodology is defined as well as what should be the data sample size and from where data has been collected. Furthermore, it is also about research approach for measuring data with quantitative technique and research design. Further, it is explained the chapter four and research purpose. Primary data source has been used and target population

13 Leonidou et al., Cultural Drivers and Trust Outcomes of Consumer Perceptions of Organizational Unethical Marketing Behavior. 
18 and above in this study. It is also described the hypothetical relationship among the variables.

It has been used quantitative approach in this research. For the reason behind it, when findings are not been recognized through statistical tools and procedures than qualitative approach is selected for the purpose. For measuring the numerical data quantitative approach help to collect the data from different population $(\mathrm{N}=350)$ e.g. students, housewives, employed, unemployed and own business. This study based on the comprising the item the variables used derived from a past literature on 5-point Likert scale. Furthermore, data was composed from Karachi only. Here, for testing the model used structural equation model to find out the relationship between the variables.

The research design for the research used correlational analysis. For the reason behind it correlation 54is a statistical technique to describe the relationship between pairs of variables as well as association among dependent along with independent variables ${ }^{14}$. For this reason, the study design is used in which exploratory factor analysis and reliability testing was done through software SPSS. 22.0 version. Further, applied advanced statistical technique through software Amos 22.0 in which confirmatory factor analysis and structural equation model is being evaluated. For the reason behind it in this research, there are three mediators.

14 J. Pallant, SPSS Survival Manual. (Philadelphia: Open University Press., 2001). 


\section{Data and Sampling}

In this research convenience, sampling is used. The sample size has been used for conducting these study $n=50$ respondents have age 18 and above male and female in district Karachi of Pakistan. For the reason behind it, to show the reliability it is needed standard size of dataset and sample size is ensure the reliability of data.

Instruments Survey questionnaire is used for data collecting instrument for this study. Here, the whole study completely depends upon on quantitative data, distributed among the male and female respondents. The variables used in the data collection instruments are Power distance, Uncertainty avoidance, Masculinity, Individualism, Self-Importance, Idealism, Product, Price, Promotion, Distance and Trust.

\section{Face and Content Validity of the Instrument}

The validity of a scale refers to the degree to which it measures and content validity refers to the satisfactoriness among which a compute or scale has sampled from the intended universe as well a field of content ${ }^{15}$. The instrument designed by (Leonidou et al., 2013) and validate by:

a) Senior teacher of Marketing as well as professional 1

b) Senior teacher of Marketing as well as professional 2

c) Senior teacher of Marketing as well as professional 3

\subsection{Reliability of Measuring Scale}

According to Pallant (2011), the reliability of scale depends on the sample size and it is required to check the every scale is reliable with the particular sample. Perfectly, Cronbach alpha coefficient of a scale should be above $0.7^{16}$. Nevertheless, Cronbach alpha coefficient values are quite sensitive with the number of item in the scale and it shows the internal consistency the value above the 0.7 well throughout acceptable.

$$
\begin{aligned}
& \text { Statistical Model of the Study } \\
& \text { SI }=\alpha+\beta 1 \text { (Ind) }+\mathrm{e} \\
& \text { SI }=\alpha+\beta 1 \text { (Mas) +e } \\
& \text { IDL }=\alpha+\beta 1 \text { (PD) }+\mathrm{e} \\
& \\
& 15 \text { Pallant. } \\
& 16 \text { Pallant. }
\end{aligned}
$$




$$
\begin{aligned}
& \mathrm{IDL}=\alpha+\beta 1(\mathrm{UA})+\mathrm{e} \\
& \mathrm{PROD}=\alpha+\beta 1(\mathrm{SI})+\mathrm{e} \\
& \mathrm{PRI}=\alpha+\beta 1(\mathrm{SI})+\mathrm{e} \\
& \mathrm{PRO}=\alpha+\beta 1(\mathrm{SI})+\mathrm{e} \\
& \mathrm{DIS}=\alpha+\beta 1(\mathrm{SI})+\mathrm{e} \\
& \mathrm{PROD}=\alpha+\beta 1(\mathrm{IDL})+\mathrm{e} \\
& \mathrm{PRI}=\alpha+\beta 1(\mathrm{IDL})+\mathrm{e} \\
& \mathrm{PRO}=\alpha+\beta 1(\mathrm{IDL})+\mathrm{e} \\
& \mathrm{DIS}=\alpha+\beta 1(\mathrm{IDL})+\mathrm{e} \\
& \mathrm{T}=\alpha+\beta 1(\mathrm{PROD})+\mathrm{e} \\
& \mathrm{T}=\alpha+\beta 1(\mathrm{PRI})+\mathrm{e} \\
& \mathrm{T}=\alpha+\beta 1(\mathrm{PRO})+\mathrm{e} \\
& \mathrm{T}=\alpha+\mathrm{DIS} \beta 1(\mathrm{DIS})+\mathrm{e}
\end{aligned}
$$

The questionnaire distributed for collecting data from different respondent's male and female, which are 18, and above. The target population are very much aware from the products its price and promotions. Hence, for checking the unethical marketing as well as exceed price of the products, these target population would be beneficial for the firms to maintain the ethical boundaries. The Likert scaling technique is use for data collection. The Likert scale allotted to the scaling 1 to 5 . The number 1 is indicate for strongly disagree, the number 2 is indicate for disagree, the number 3 is represent undecided, the number 4 is indicate agree and the number 5 is indicate for strongly agree. Primary data source is use in this research.

There are 11 variables that is use to explain in this study 10 independents and 1 dependent variable. Those are uncertainty avoidance, power distance, masculinity, individualism, self-importance, idealism, perceived unethical marketing (product, price, promotion, distance) and trust. DV In this research we have 1 dependent variable which having name trust. Trust is describe like customer willingness to depend on their expectations concerning a firm or organization upcoming behavior ${ }^{17}$. Furthermore, consumers trust on a firm's actions extremely reliant on the level of ethical practices, which is concerning product, price, promotion and distribution promotion $^{18}$.

17 Walsh et al., "The Effect of Consumer Confusion Proneness on Word of Mouth , Trust , and Customer Satisfaction."

18 Leonidou et al., Cultural Drivers and Trust Outcomes of Consumer Perceptions of Organizational Unethical Marketing Behavior. 
There are 10 independent variables are used in this study. First one is uncertainty avoidance is first cultural dimension that can be explained form extent of an individual capability to control successfully throughout uncertain, unstructured, unclear, changeable, or unidentified situations. Second independent variables power distance that is second cultural dimension can be define as degree to people, particularly subordinate and followers accept and be expecting not the same distribution of authority and power contained by a group of people. Now, third independent variable of cultural dimension is masculinity that is describe as masculinity against femaleness. In general, it is about the gender and distribution of responsibility recognized. Further, masculinity and femaleness is demonstrate through by assertiveness and Modesty in the same way ${ }^{19}$. Here, fourth independent variable of cultural dimension is individualism, which is explain as individualism against collectivism make a distinction among people that do support self- interest and loose social binding in opposition to common interest as well as close attachment and social bindings. The fifth independent variable is ethical ideology that is described as the level of desirable consequences are being accomplish through providing above the ground achievement are taken. Moreover, ethics theory by (EPT; Forsyth, 1980) explained that is individual have a power over delicate moral philosophies, which can be guided there, procedures, judgments and response in diverse framework. Now, the sixth independent variable which is self-importance that is explained by empirical studies egoistic people can be uninterested with the firm or organization's unethical marketing practices for the time when self-interest on risk is not putting by them. Further, egoism or self-importance defined that an individual take his/her own interest greater than others $\mathrm{do}^{20}$. Here, perceived unethical marketing behavior under this variable there are four sub variable product price promotions and distribution that is also called marketing 4 Ps and that are going to describe unethical marketing behavior. Product is the goods, services e.g. variety, excellence, design, features, brand name, packaging, and services, which a company offered to the target market. Price is the amount of money e.g. list price, discounts, allowances, payments periods, credit terms which a customer pay to take the product. Now, promotion is the activities

19 Brent Smith, "Who Shall Lead Us? How Cultural Values and Ethical Ideologies Guide Young Marketers ' Evaluations of the Transformational Manager - Leader," 2011, 63345, https://doi.org/10.1007/s10551-010-0701-0.

20 Leonidou et al., Cultural Drivers and Trust Outcomes of Consumer Perceptions of Organizational Unethical Marketing Behavior. 
e.g. advertising, personal selling, sales promotion, public relation that can communicate the qualities of the product as well as influence the target consumers to pay money for it. Distribution or place is the company's activities e.g. channels, coverage, location, inventory, transportation, logistics that is making the product available for the target customers ${ }^{21}$.

\section{Ethical Consideration}

Primary data collection directly engages the respondents about the subject of research. Further, it is also include the information about the research topic and researcher should do care about their respondents. For the reason behind it, the primary research has details about analysis, surveys, observations and interviews. Hence, the research, conducted for academic purpose as well as for professionals who should know the ethics behind research doings ${ }^{22}$. The information collected from the respondents will remain secret and make sure that this data is use only for the research.

\section{Parametric Assumptions}

When the data is distributed and collected there are, three parametric assumptions, which should be consider before working on data, called data screening. The uni-variate and multivariate outliers must be detecting as well as deleted and there is no missing value in the data. Further, data should be normally distribute. Outliers are the excessive values in dataset. According to Tabachnick and Fidell (2007) "univariate outliers are cases with extreme value one variable as well as multivariate outliers are cases with an unusual combination of scores on two or more variables". For univariate outliers detecting with standardized zscore value which greater than 3.29 and in this study there is two univariate outliers detected. Further, multivariate outliers detecting with Mahilanoble's distance value, which is less than $\mathrm{p}<0.001$, confirmed outliers and in this study, there are 41 multivariate outliers that is delete from the dataset.

Kottler. P \& Armstrong. G., Principle of Marketing, 14th ed. (Boston: Pearson, 2011).

L. S. Tabachnick, B. G., \& Fidell, Using Multivariate Statistics. (New York: Pearson, 2007). 
Table: 1 Assessing Univariate Outliers

Using Standardized Z-score

2

Table: 4.2.1.2 Assessing Multivariate Outliers

Mahalanobis Distance (cut-off value $=29.59$ at $99.99 \%$ confidence interval)

41

4.3.2 Outliers removed in total

\begin{tabular}{|c|c|c|c|}
\hline $\begin{array}{c}\text { Kinds of } \\
\text { Outlier }\end{array}$ & $\begin{array}{c}\text { No. of outliers } \\
\text { removed }\end{array}$ & $\begin{array}{c}\text { The Process used } \\
\text { for outliers }\end{array}$ & $\begin{array}{c}\text { Sample Size } \\
\text { (after removing } \\
\text { outliers) }\end{array}$ \\
\hline Univariate & 2 & $\begin{array}{c}\text { Standardized Z } \\
\text { Score }\end{array}$ & $350-2=348$ \\
\hline Multivariate & 41 & $\begin{array}{c}\text { Mahalanobis } \\
\text { Distance }\end{array}$ & $348-41=307$ \\
\hline
\end{tabular}

Missing value analysis facilitates to address problems that are caused by incomplete data. Missing values effect the results of the data that can be misled. Therefore, less information can be reduce accuracy of calculation of statistics and one more concern is that statistical measures are support complete study as well as cases and the assumption behind it missing values can make difficult the theory mandatory. Hence, in this study there is less than 10 percent missing values that is remove by 4 point method of mean in likert scale data as well as 4 point method of median in categorical data. It is data reduction technique. The large set of data items of variable can reduce into small set of factor and it is call components. Exploratory factor analysis is repeatedly use in near the beginning phase of research for collecting the information about the interrelationship between the dataset of variables ${ }^{23}$. Now, for the exploratory factor analysis executed to estimate the 58 items

23 Pallant, SPSS Survival Manual. 
of instrument to extract the dimension of every construct. There are 11 factor were requested for the reason behind it the instrument for 11 factor should be construct help of varimax rotation in IBM SPSS 22.0 version. Here, the dependent variable is trust and independent variables are power distance, uncertainty avoidance, masculinity, individualism, idealism, and self-importance, unethical marketing behavior (product, price, promotion, and distance).

Table 2 KMO and Bartlett's Test

\begin{tabular}{|c|l|c|}
\hline \multicolumn{2}{|c|}{ KMO and Bartlett's Test } \\
\hline Kaiser-Meyer-Olkin Measure of Sampling Adequacy. & .806 \\
\hline \multirow{2}{*}{$\begin{array}{c}\text { Bartlett's Test of } \\
\text { Sphericity }\end{array}$} & Approx. Chi-Square & 2189.833 \\
\cline { 2 - 3 } & Df & 465 \\
\cline { 2 - 3 } & Sig. & .000 \\
\hline
\end{tabular}

Consequently, the value of Kaiser Meyer Olkin (KMO) was calculated 0.806 and that is capable for satisfactory sample is ready to go for exploratory factor analysis. Furthermore, it is significant outcome of Bartlett's Test Sphericity $\mathrm{p}<0.05$ describes the matrix is not identity matrix. The above table shows the Bartlett's Test outcomes 
The impact of cultural drivers on trust: A multi-level study of self-importance, idealism and unethical marketing behavior

Table 4.3.2 Rotated Component Matrix

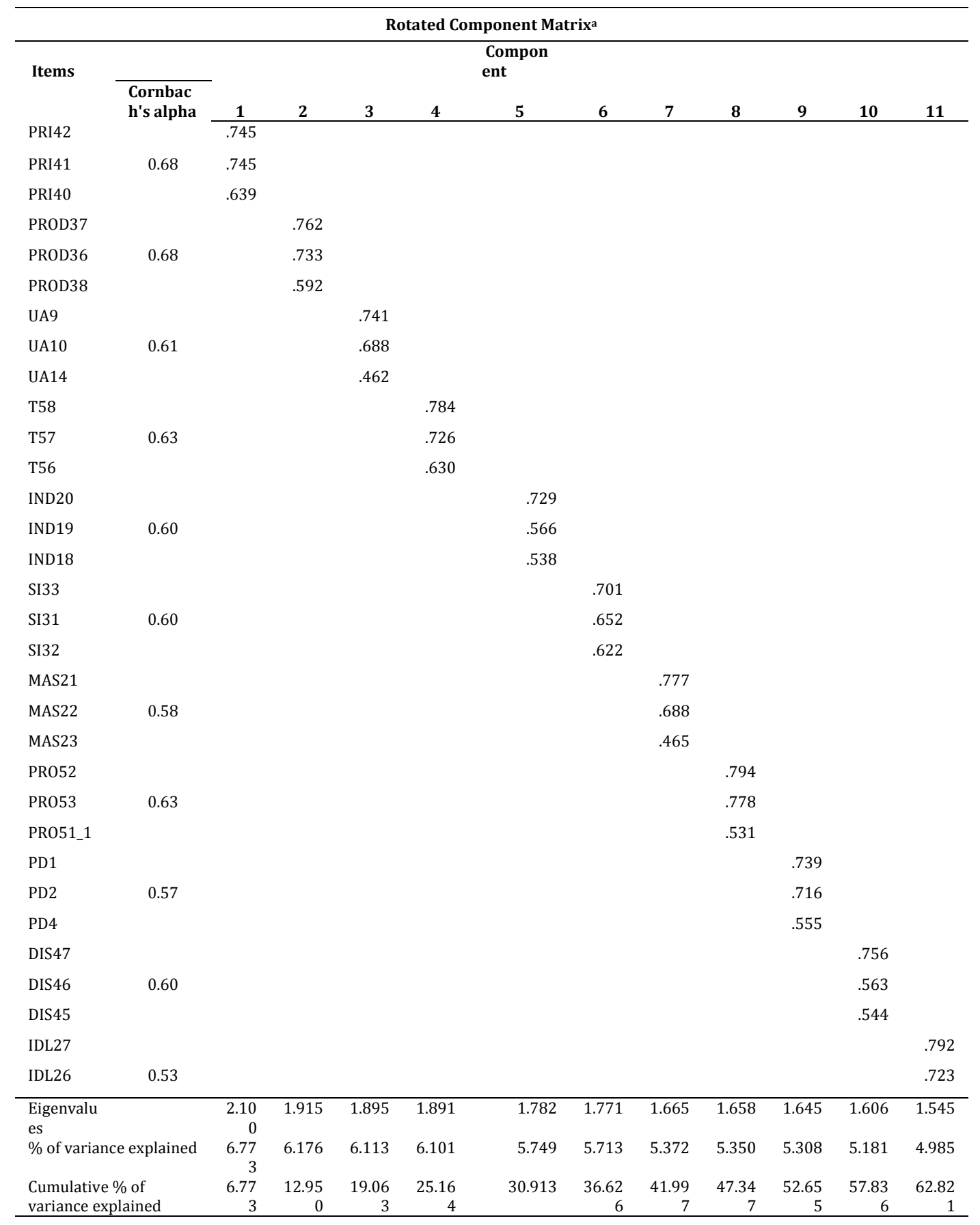




\subsection{Validity}

It is described by Pallat (2011) that it is refer to the degree of determine what and which is supposed to calculate. Here, the validation process depends upon on three types of validity regarding exploratory factor analysis that is construct validity, discriminant validity and convergent validity.

\subsubsection{Construct validity}

It is describe by testing scale not in a favor of a particular standard other than in term of hypothetically concerning the nature of essential variable as well as construct ${ }^{24}$. Now, in this study each variable loaded in their own factor that is why construct validity ensured.

\subsubsection{Convergent validity}

There is value of all factors 0.5 and greater so they are heavily loaded and two variables have less than 0.5 but it is acceptable. Therefore, convergent validity ensured 25 .

\subsubsection{Discriminant validity}

It is describe by the testing scale there is unrelated factors as well as no cross loading every factor loaded in their own group. Now discriminant validity is also ensure 26 .

\subsection{Confirmatory factor analysis}

It is more difficult or complex technique used in research to test for confirm the specific hypothesis regarding formation of set of variables ${ }^{27}$. Further, in this phase confirmatory factor analysis, be performed to test the dimension of this model on the cultural drivers, unethical marketing practices and trust. There are 11 factor and 32 items to described the specifically power distance, uncertainty avoidance, masculinity, individualism, idealism, and selfimportance, unethical marketing behavior (product, price, promotion, and

\footnotetext{
24 Pallant.

25 Pallant.

26 Pallant.

27 Pallant.
} 
The impact of cultural drivers on trust: A multi-level study of self-importance, idealism and unethical marketing behavior

distance) and trust. The below table is represents the outcome of convergent validity and reliability of the construct in adding Cronbach alpha.

Table 4.5.1: Instrument construct validity and composite reliability

Table 5: Instrument construct validity and composite reliability

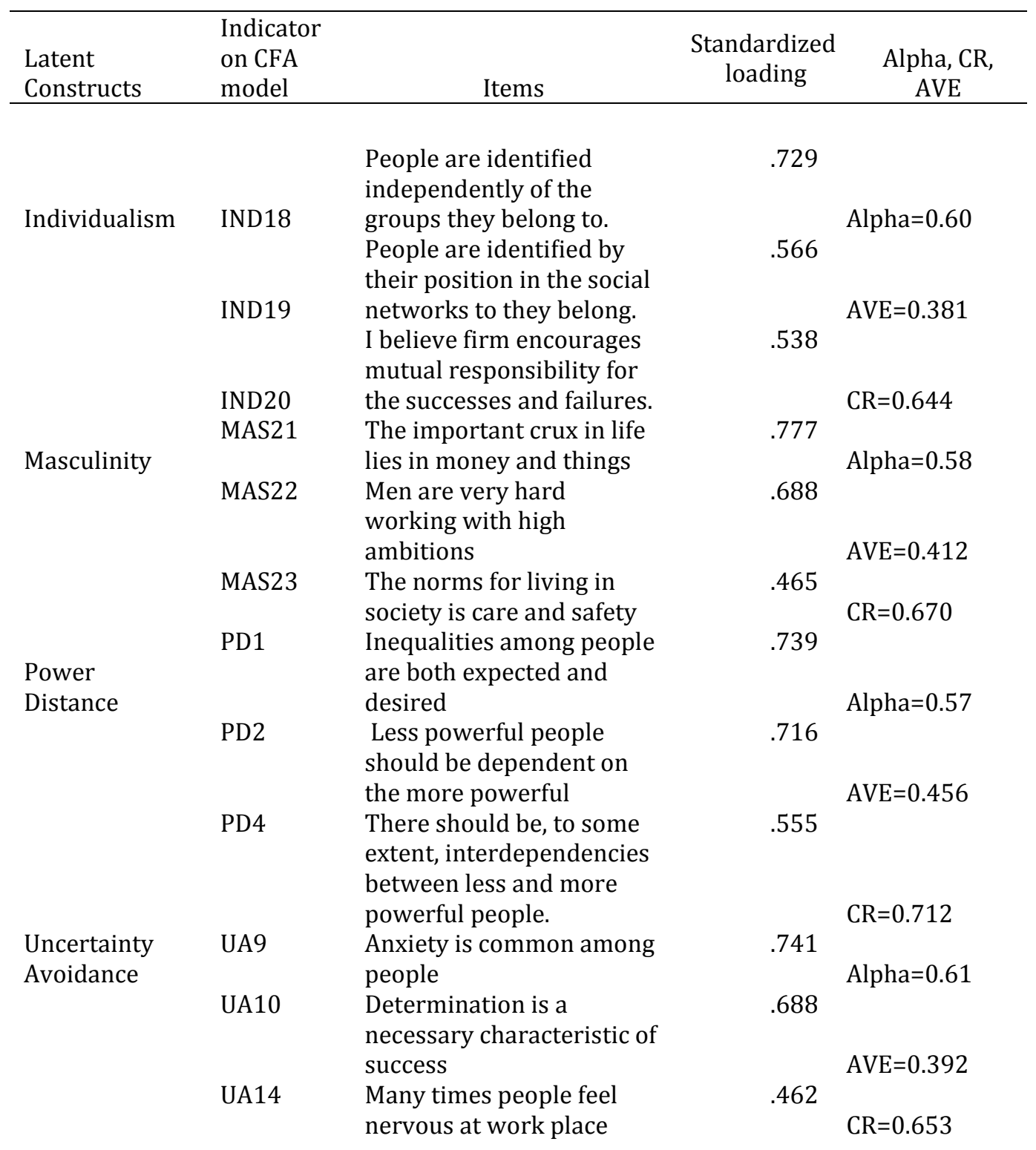


Jhss, Vol. 8, No. 2 , July to December, 2017

Self-

SI33 People's activities should

.701

Importance

be followed by

uniqueness.

Alpha $=0.60$

SI31 An action is right if it leads

.652

to the greatest good for

the greatest number of

people

$\mathrm{AVE}=0.434$

SI32 People should be

.622

concerned about

maximizing social welfare,

rather than personal

interests

IDL27 I criticize the ethicality

based on situational

factors, rather than

objectively justifiable

Idealism

principles

Alpha $=0.53$

IDL26 There are no universal

principles or ethical rules

that can be applied to

every situation

$\mathrm{AVE}=0.575$

$\mathrm{CR}=0.730$

PROD37 Firms use labeling, that is

not implied, prominently

visible, and easily

Product

understood

Alpha $=0.68$

PROD36 Firms do not provide, or

.733

hide information, about

ingredients, country of

origin, and expiry date

AVE $=0.490$

PROD38

Firms use oversize

.592

packages that mislead

consumers about how

much of the product it

contains

$\mathrm{CR}=0.740$

PRI42 Firms quote different

.745

prices for different buyers

(e.g. minorities), although

products are the same

Alpha $=0.68$

Firms put price artificially

.745

high and then reduce it to

make the buyer feel that

he made a good deal

AVE $=0.506$

PRI40

Firms agree between them

to sell their products to

consumers at a higher

price

$\mathrm{CR}=0.753$ 
The impact of cultural drivers on trust: A multi-level study of self-importance, idealism and unethical marketing behavior

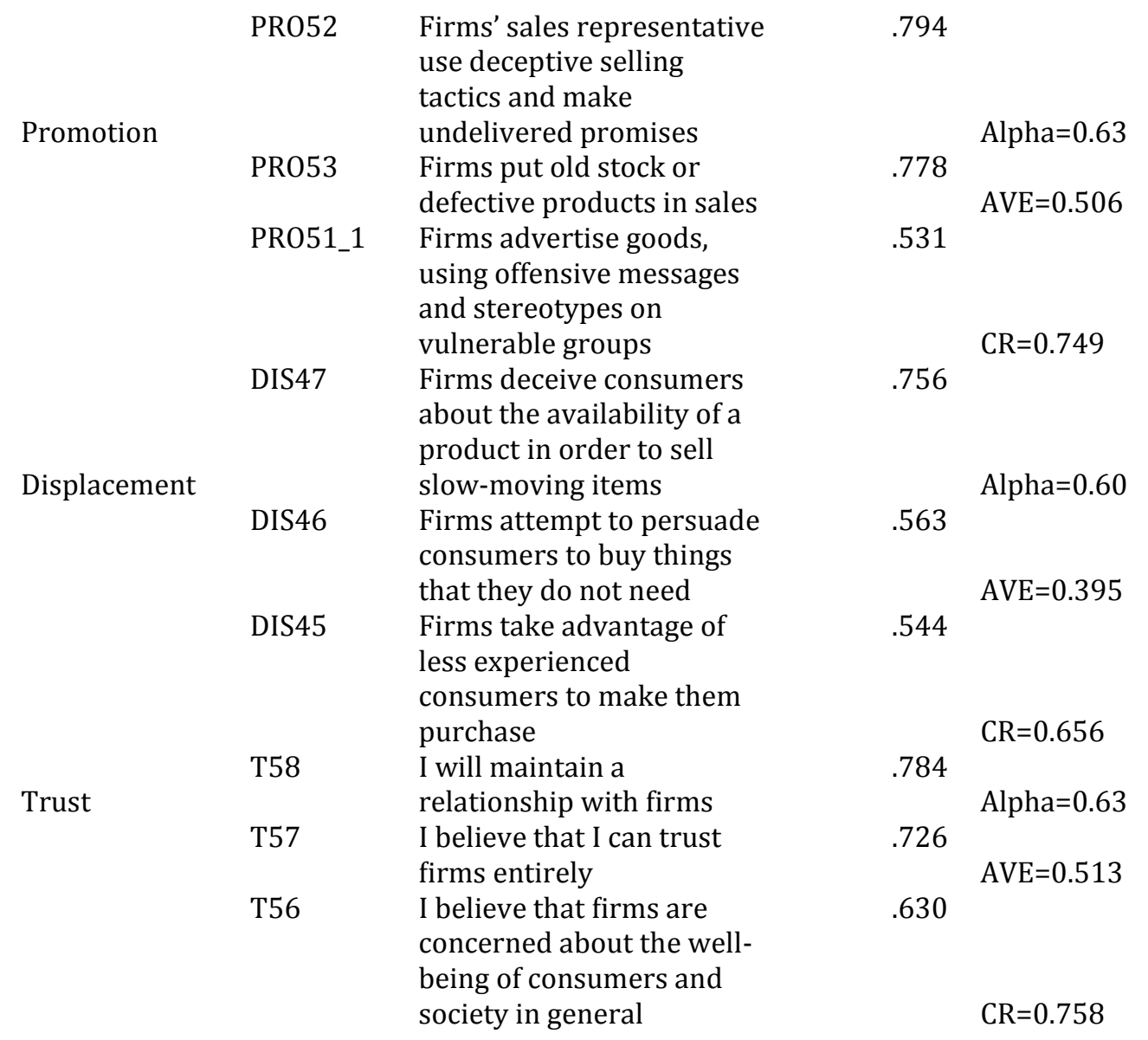

Furthermore, there are also describing composite reliability (CR), and average variance explained (AVE) for each one of the 11 latent constructs. Overall, the calculation is good some of few exceptions and more or less all of the constructs have CR and AVE fine over 0.70 and 0.50 in that order (Hair et al. 2010; Molinaet al. 2007). 
Jhss, Vol. 8, No. 2 , July to December, 2017

Table 4.5.2 Measures of model fit

\begin{tabular}{lccccccc}
\hline $\begin{array}{l}\text { Goodness of } \\
\text { fit measures }\end{array}$ & CMIN/DF & P-Value & GFI & AGFI & TLI & CFI & RMSEA \\
\hline $\begin{array}{l}\text { Recommended } \\
\text { value }\end{array}$ & $<5^{\mathrm{a}}$ & Insignificant & $\geq 0.85^{\mathrm{a}}$ & $\geq 0.80^{\mathrm{c}}$ & $\begin{array}{c}\text { Close } \\
\text { to } 1^{\mathrm{d}}\end{array}$ & $\geq 0.95^{\mathrm{c}}$ & $\begin{array}{c}\leq .05\left(>0.5^{\mathrm{e}}\right) \\
\text { CFA model }\end{array}$ \\
1.4 & 0.899 & 0.87 & 0.896 & 0.914 & 0.036 & 1.4 \\
$\begin{array}{l}\text { Structural } \\
\text { model }\end{array}$ & 1.433 & 0.893 & 0.87 & 0.887 & 0.901 & 0.038 & 1.433 \\
\hline
\end{tabular}

Notes: $\mathrm{a}=$ Byrne (2010); $\mathrm{b}=$ (Hair et al., 2010) at p. 647 stated that a significant value may be expected (even with good fit) if the sample size is less than 250 with 12 to 30 observed variables; $\mathrm{c}=$ Bagozzi and Yi (1988); $\mathrm{d}=$ Bentler (1990); e =Browne and Cudeck (1993); $\mathrm{f}=$ the model is recursive. All values are rounde to two decimal places Furthermore, the measurement model to measure the goodness of fit, there are six general measures according to Segars and Grover (1998), Lin, and Lee $(2004,2005)$. That are the ratio of x2statistics to the degree of freedom (df), comparative fit index (CFI), goodness-of-fit index (GFI), adjusted goodness-of-fit index (AGFI), named fit index (NFI) and root mean square error of approximation (RMSEA). Here, the values are of CMIN/DF $=1.4, \mathrm{GFI}=0.899$, NNFI(TLI) $=0.896, \mathrm{CFI}=0.914$ and REMSEA $=0.036$. overall, all values are of model fit less or greater than recommended values and that is good result which is measurement model represented as well as very good fit with the collection of dataset of this research . 
The impact of cultural drivers on trust: A multi-level study of self-importance, idealism and unethical marketing behavior

\section{Structural model}

It is highlighting the relationship between unobserved variables by the structural model (Byrne 2010). The above table 4.6 represents the overall results as well as outcomes of the structural model analysis. Further, Fig. 2 shows the structural model as well as model good fit that is explained by the Chi Square index (CMIN/DF $=1.433$ ) and other indices (GFI= 0.893; $\mathrm{AGFI}=0.87$; NNFI $0.887 ; \mathrm{CFI}=0.901 ; \mathrm{RMSEA}=0.038$ ). Here, the all values of model fit indices realistically go beyond the recommended values that are satisfactory fit to the sample collected for structural model ${ }^{28}$.

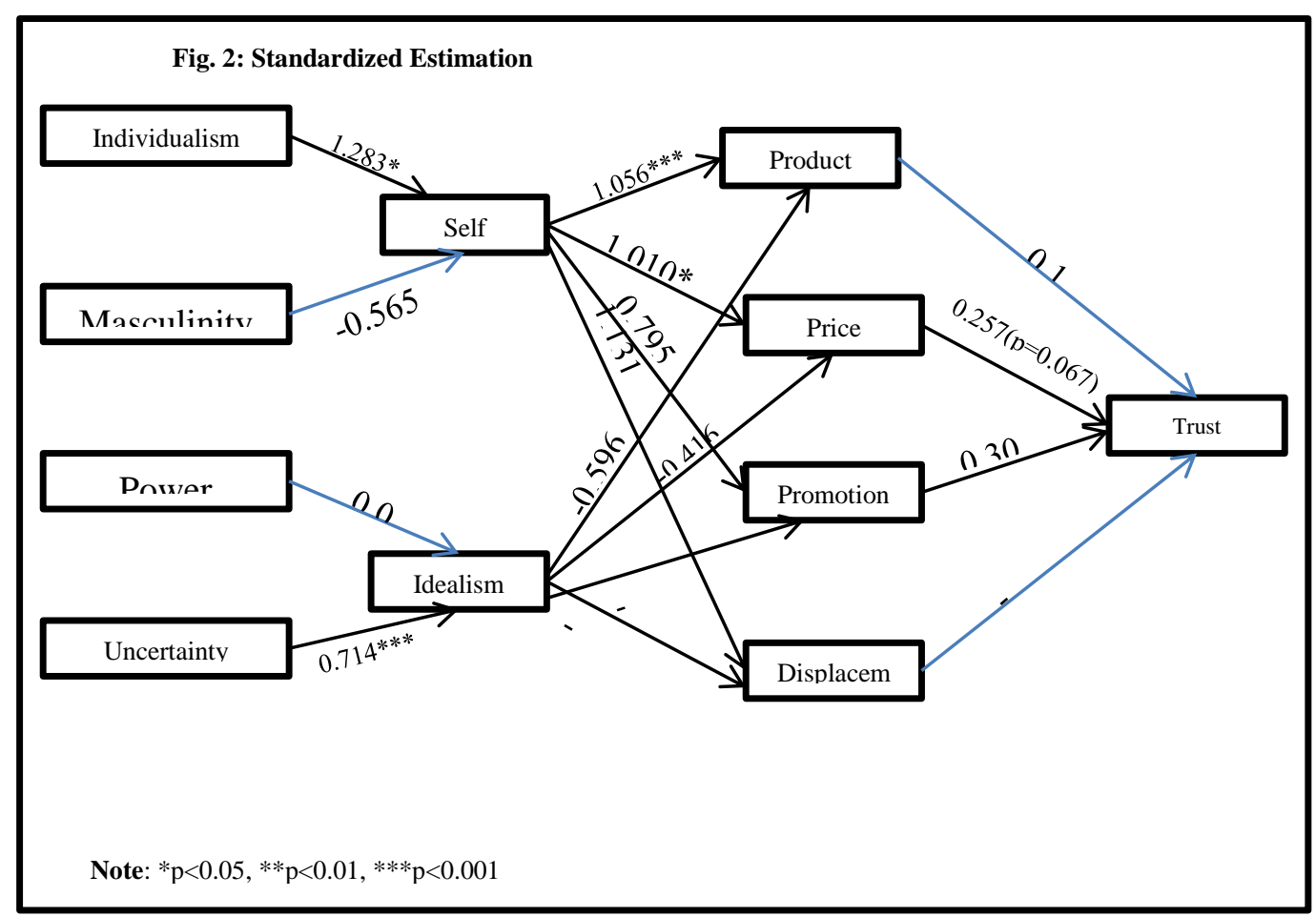

28 Muhammad Shahnawaz Adil, "Strategic Human Resource Management Practices and Competitive Priorities of the Manufacturing Performance in Karachi," no. 1995 (2014), https://doi.org/10.1007/s40171-014-0084-7. 
The measurement of structural model are recursive in nature and the recursive model is type of structural models have two basic features: "(a) it stipulates the direction of cause from one direction only"29 i.e., unidirectional; and (b) "their disturbances are uncorrelated"30.

\section{Hypothesis testing}

For define the validity of hypothesized paths and statistical significance for overall structural model values. Now, the results from analysis performed are significant. For Individualism and self-importance (path coefficient $=$ 1.283; $\mathrm{p}<0.001$ ), uncertainty avoidance and idealism (path coefficient $=$ $0.714 ; \mathrm{p}<0.001$ ), self-importance and product (path coefficient $=1.056 ; \mathrm{p}$ $<0.001$ ), self-importance and price (path coefficient $=1.010 ; p<0.001$ ), selfimportance and promotion (path coefficient $=0.795 ; \mathrm{p}<0.001$ ), selfimportance and displacement (path coefficient $=1.131 ; \mathrm{p}<0.001$ ), idealism and product (path coefficient $=-0.596 ; \mathrm{p}<0.004$ ), idealism and price (path coefficient $=-0.416 ; \mathrm{p}<0.026$ ), idealism and promotion (path coefficient $=$ $0.231 ; \mathrm{p}<0.163$ ), idealism and displacement (path coefficient $=-0.513 ; \mathrm{p}$ $<0.017$ ), price and trust (path coefficient $=0.257 ; \mathrm{p}<0.067$ ), and last significant value promotion and trust (path coefficient $=0.302 ; \mathrm{p}<0.014$ ). Here, four hypotheses which are not supported; they are H2, H3, H13 and H16 respectively.

29 Barbara M. Byrne, Structural Equation Modeling with AMOS: Basic Concepts, Applications, and Programming. (New York:Routledge., 2010).

30 R.B. Kline, Principles and Practice of Structural Equation Modeling. (Guilford Press, New York., 2011). 
The impact of cultural drivers on trust: A multi-level study of self-importance, idealism and unethical marketing behavior

Table. 3. Construct measurement summary: CFA and composite reliability

\begin{tabular}{|c|c|c|c|c|c|c|c|}
\hline $\begin{array}{l}\text { Path } \\
\text { regression }\end{array}$ & & & Estimate & S.E & C.R. & $\mathrm{P}$ & Label \\
\hline SI_ & $<---$ & $\begin{array}{l}\text { IN } \\
D\end{array}$ & 0.993 & $\begin{array}{c}0.3 \\
11\end{array}$ & 3.191 & $\begin{array}{l}0.0 \\
01\end{array}$ & $\begin{array}{l}\text { support } \\
\text { ed }\end{array}$ \\
\hline $\mathrm{SI}_{-}$ & $<---$ & $\begin{array}{c}\mathrm{M} \\
\mathrm{AS}_{-}\end{array}$ & -0.344 & $\begin{array}{l}0.2 \\
03\end{array}$ & -1.697 & $\begin{array}{l}0.0 \\
9\end{array}$ & $\begin{array}{c}\text { Not } \\
\text { supported }\end{array}$ \\
\hline IDL_ & $<---$ & $\begin{array}{l}\text { PD } \\
-\end{array}$ & 0.047 & $\begin{array}{l}0.1 \\
46\end{array}$ & 0.321 & $\begin{array}{l}0.7 \\
49\end{array}$ & $\begin{array}{c}\text { Not } \\
\text { supported }\end{array}$ \\
\hline IDL_ & $<---$ & $\begin{array}{l}\text { UA } \\
-\end{array}$ & 0.826 & $\begin{array}{l}0.1 \\
94\end{array}$ & 4.255 & $* * *$ & $\begin{array}{l}\text { support } \\
\text { ed }\end{array}$ \\
\hline Prod & $<---$ & $\mathrm{SI}_{-}$ & 2.644 & $\begin{array}{l}0.6 \\
31\end{array}$ & 4.19 & $* * *$ & $\begin{array}{l}\text { Support } \\
\text { ed }\end{array}$ \\
\hline Pric & $<---$ & $\mathrm{SI}_{-}$ & 2.079 & $\begin{array}{l}0.5 \\
03\end{array}$ & 4.133 & $* * *$ & $\begin{array}{l}\text { support } \\
\text { ed }\end{array}$ \\
\hline Pro & $<---$ & $\mathrm{SI}_{-}$ & 1.57 & $\begin{array}{c}0.4 \\
11\end{array}$ & 3.818 & $* * *$ & $\begin{array}{l}\text { support } \\
\text { ed }\end{array}$ \\
\hline DIS_ & $<---$ & $\mathrm{SI}_{-}$ & 1.527 & $\begin{array}{l}0.3 \\
99\end{array}$ & 3.83 & $* * *$ & $\begin{array}{l}\text { support } \\
\text { ed }\end{array}$ \\
\hline Prod & $<---$ & $\begin{array}{l}\text { ID } \\
\mathrm{L}_{-}\end{array}$ & -0.884 & $\begin{array}{l}0.3 \\
1\end{array}$ & -2.849 & $\begin{array}{l}0.0 \\
04\end{array}$ & $\begin{array}{l}\text { Support } \\
\text { ed }\end{array}$ \\
\hline Pric & $<---$ & $\begin{array}{l}\text { ID } \\
\mathrm{L}_{-}\end{array}$ & -0.507 & $\begin{array}{l}0.2 \\
28\end{array}$ & -2.228 & $\begin{array}{l}0.0 \\
26\end{array}$ & $\begin{array}{l}\text { support } \\
\text { ed }\end{array}$ \\
\hline Pro & $<---$ & $\begin{array}{l}\text { ID } \\
\mathrm{L}_{-}\end{array}$ & -0.27 & $\begin{array}{l}0.1 \\
93\end{array}$ & -1.394 & $\begin{array}{l}0.1 \\
63\end{array}$ & $\begin{array}{l}\text { support } \\
\text { ed }\end{array}$ \\
\hline DIS_ & $<---$ & $\begin{array}{l}\text { ID } \\
\mathrm{L}_{-}\end{array}$ & -0.411 & $\begin{array}{l}0.1 \\
72\end{array}$ & -2.382 & $\begin{array}{l}0.0 \\
17\end{array}$ & $\begin{array}{l}\text { support } \\
\text { ed }\end{array}$ \\
\hline $\mathrm{T}$ & $<---$ & $\begin{array}{l}\text { Pr } \\
\text { od }\end{array}$ & 0.101 & $\begin{array}{l}0.1 \\
03\end{array}$ & 0.975 & $\begin{array}{l}0.3 \\
3\end{array}$ & $\begin{array}{c}\text { Not } \\
\text { supported }\end{array}$ \\
\hline $\mathrm{T}$ & $<---$ & $\begin{array}{l}\text { Pri } \\
\mathrm{c}\end{array}$ & 0.249 & $\begin{array}{l}0.1 \\
36\end{array}$ & 1.831 & $\begin{array}{c}0.0 \\
67\end{array}$ & $\begin{array}{l}\text { support } \\
\text { ed }\end{array}$ \\
\hline $\mathrm{T}$ & $<---$ & $\begin{array}{l}\operatorname{Pr} \\
0\end{array}$ & 0.306 & $\begin{array}{l}0.1 \\
24\end{array}$ & 2.469 & $\begin{array}{l}0.0 \\
14\end{array}$ & $\begin{array}{l}\text { support } \\
\text { ed }\end{array}$ \\
\hline $\mathrm{T}$ & $<---$ & $\begin{array}{l}\text { DI } \\
\mathrm{S}_{-}\end{array}$ & -0.269 & $\begin{array}{l}0.2 \\
48\end{array}$ & -1.082 & $\begin{array}{l}0.2 \\
79\end{array}$ & $\begin{array}{c}\text { Not } \\
\text { supported }\end{array}$ \\
\hline
\end{tabular}




\section{Discussion}

It is describing that overall outcomes of structural analysis explain the structural relationship in between four cultural drivers (power distance, uncertainty avoidance, masculinity and individualism) and trust as well as unethical marketing behavior which includes marketing four piece (product, price, promotion \& displacement).

Here, individualism has positive on self-importance that is the element of cultural driver's. Moreover, in this research self-importance is positively impact on unethical marketing behavior concerning product price promotion and displacement. Further, self-importance has strong positive impact on each element of marketing component that is represent the unethical marketing behavior. H5, H6, H7, and $\mathrm{H} 8$ have the significant impact of selfimportance $\mathrm{H} 1$.

Furthermore, unethical marketing practices have significantly effect on trust regarding Price and promotion if the marketers consider the two aspects that will beneficial for them as well as consumers. The statistically results shows that price and promotion in marketing practices is being important to gain the consumer trust for firms.

In contrast, in previous research there was negatively impact on selfimportance as well as egoistic behavior of unethical marketing behavior ${ }^{31}$. For the reason behind it, marketing unethicality, ethical perceptions concerning the firms increase the impact of consumer value on customer satisfaction along with eventually loyalty and suppliers can count on their ethical reputation to be a value booster ${ }^{32}$.

In addition, consumer stress should not rest of entire accountability for marketing unethicality on firm or organization and develop an ethical consumer approach that will reward ethical and punish unethical firms ${ }^{33}$. Therefore, this research elaborate the two cultural drivers are creates the significant contribution on developing consumer trust.

31 Leonidou et al., Cultural Drivers and Trust Outcomes of Consumer Perceptions of Organizational Unethical Marketing Behavior.

32 Mulki and Jaramillo, "Ethical Reputation and Value Received : Customer Perceptions."

33 Leonidou et al., Cultural Drivers and Trust Outcomes of Consumer Perceptions of Organizational Unethical Marketing Behavior. 
Here, uncertainty avoidance on idealism has highly positively effect that is the aspect of cultural driver's. Therefore, $\mathrm{H} 4$ has positive value that impact on idealism. According to (Leonidou et al., 2013) there are well built positive relationship among idealism and unethical marketing behavior that is idealistic consumer are very much concerned regarding unethical marketing practices. Consequently, in this research idealism has negative impact on unethical marketing behavior that is a product price promotion and displacement.

Hence, there is significance of key demographic factors (income, gender, and race) in understanding consumers' perceptions of socially responsible marketing as well as marketing practices of firms ${ }^{34}$, and to satisfy their need, personal desire as well as wants which are unavailable people may indifferent to other people that is the reason of unethical marketing behavior of firm ${ }^{35}$.

\section{Conclusion}

Now, in conclusion the objective of the research is to find the impact of cultural drivers on trust mediating unethical marketing behavior, idealism and self-importance on firm in Karachi. The empirical studies show that the cultural drivers (individualism and uncertainty avoidance) have positive effect on self-importance and idealism and other two (masculinity and power distance) have not supported the model. Here, in this study self- importance has highly positive significant effect on unethical marketing behavior hypothesis H5, H6, H7 and H8 highly positively supported self-importance but previous research results shows the negative effect on unethical marketing behavior. Hence, it is said that are people more concern about their self, their benefits and to satisfy their needs only and do not care about ethical behavior of firms. The positive relationship among individualism and self-importance provides a clear signal that the boundless concern of unique members of culture in their personal interests plus goals might result in selfimpotence attitude.

34 Anthony Patino et al., "Differences How Important Are Different Socially Responsible Marketing Practices? An Exploratory Study of Gender , Race , and Income Differences," 2014, https://doi.org/10.1108/JCM-10-2013-0733.

35 Leonidou et al., Cultural Drivers and Trust Outcomes of Consumer Perceptions of Organizational Unethical Marketing Behavior. 
Further, idealism has negative impact on unethical marketing behavior the hypotheses are $\mathrm{H} 9, \mathrm{H} 10, \mathrm{H} 11$ and $\mathrm{H} 12$ have negative but significant values and support the unethical marketing behavior. Furthermore, it is describing that people are idealistic but has negative relationship with unethical marketing behavior and in previous research it has positive effect but in this study has negative. This study has implication on marketing area and consumer perception about the firm as well as trust also. The finding of this study price and promotion are the key element of marketing practices for gaining the trust of consumers on the firms and product and displacement has no effect on it.

\section{Recommendations}

Some recommendation from research findings are as follows:

- In this research the recommendation for marketing manager as well as management to re visit their marketing strategy and price and promotion are the main key element to get the consumer trust on firms. For the reason behind it people are more concern about price and promotion.

- $\quad$ Further, product and displacement should be consider for improvement. Here, this research make known for unethical marketing behavior and has effect on theoretical and managerial perception.

- $\quad$ The research study would be beneficial for policy maker, government, and firms as well as public.

- $\quad$ There is a need to run succeeding campaigns to convey the message to firms about the ethicality of their marketing behavior.

\section{Future Recommendations}

There are future improvement is needed with different country different sample size as well as data should be gathered from other area and future research will be with different variable as well as large data set. Further, there is more element of marketing behavior for future research and future research should be how to these four cultural drivers plays the role for gaining consumer trust on firm regarding FMCG products. For the reason behind it according to (Brunk, 2010) ${ }^{36}$ "a more thorough accepting of drivers along with outcomes of consumers' ethical perceptions should be achieved throughout well-designed qualitative research, taking the form of in-depth interviews with focus group discussions" as cited ${ }^{37}$.

36 Katja H Brunk, "Reputation Building : Beyond Our Control ? Inferences in Consumers ' Ethical Perception Formation" 292, no. July (2010): 275-92, https://doi.org/10.1002/cb.

37 Leonidou et al., Cultural Drivers and Trust Outcomes of Consumer Perceptions of Organizational Unethical Marketing Behavior. 


\section{References}

Adil, Muhammad Shahnawaz. "Strategic Human Resource Management Practices and Competitive Priorities of the Manufacturing Performance in Karachi," no. 1995 (2014). https://doi.org/10.1007/s40171-014-0084-7.

Brunk, Katja H. "Reputation Building: Beyond Our Control? Inferences in Consumers ' Ethical Perception Formation" 292, no. July (2010): 275-92. https://doi.org/10.1002/cb.

Byrne, Barbara M. Structural Equation Modeling with AMOS: Basic Concepts, Applications, and Programming. New York:Routledge., 2010.

G., Kottler. P \& Armstrong. Principle of Marketing. 14th ed. Boston: Pearson, 2011.

Kline, R.B. Principles and Practice of Structural Equation Modeling. Guilford Press, New York., 2011.

Leonidou, Leonidas C, Constantinos N Leonidou, Olga Kvasova, and Leonidas C Leonidou. Cultural Drivers and Trust Outcomes of Consumer Perceptions of Organizational Unethical Marketing Behavior, 2013. https://doi.org/10.1108/03090561311297445.

Long-Chuan Lu, Hsiu-Hua Chang, Shih-Ting Yu. "Online Shoppers ' Perceptions of e-Retailers ' Ethics , Cultural," 2013. https://doi.org/ 10.1108/10662241311295773.

Mulki, Jay Prakash, and Fernando Jaramillo. "Ethical Reputation and Value Received: Customer Perceptions," 2011. https://doi.org/10.1108/ 02652321111152891.

Pallant, J. SPSS Survival Manual. Philadelphia: Open University Press., 2001.

Patino, Anthony, Velitchka D Kaltcheva, Dennis Pitta, Ven Sriram, Robert D Winsor, and Anthony Patino. "Differences How Important Are Different Socially Responsible Marketing Practices ? An Exploratory Study of Gender , Race , and Income Differences," 2014. https://doi.org/10.1108/JCM-102013-0733. 
Smith, Brent. "Who Shall Lead Us? How Cultural Values and Ethical Ideologies Guide Young Marketers ' Evaluations of the Transformational Manager - Leader," 2011, 633-45. https://doi.org/10.1007/s10551-0100701-0.

Tabachnick, B. G., \& Fidell, L. S. Using Multivariate Statistics. New York: Pearson, 2007.

Walsh, Gianfranco, Vincent Wayne Mitchell, Gianfranco Walsh, and Vincentwayne Mitchell. "The Effect of Consumer Confusion Proneness on Word of Mouth , Trust , and Customer Satisfaction," 2010. https://doi.org/10.1108/ 03090561011032739. 